ISSN: 1130-3743 - eISSN: 2386-5660

DOI: http://dx.doi.org/10.14201/teoredu302201221

\title{
LA IMPORTANCIA DE LOS VALORES TRANSMITIDOS POR EL PROFESORADO DE SECUNDARIA PARA UNA MEJOR CONVIVENCIA ESCOLAR
}

\section{The importance of the values transmitted by the secondary teachers for a better school coexistence}

\section{L'importance des valeurs transmises par l'enseignant secondaire pour une meilleure coexistence scolaire}

Marcos García Vidal*, M. ${ }^{a}$ Carmen OrTega NAVAS** y José María Sola ReCHE***

* Universidad Nacional de Educación a Distancia. Facultad de Educación. Centro asociado Elche (Alicante). C/ Candalix,s/n.03202 Elche.marcos.garcia@elx.uned.es ** Universidad Nacional de Educación a Distancia. Facultad de Educación. C/Juan del Rosal, 14.28040 Madrid.cortega@edu.uned.es

** Universidad de Alicante. Facultad de Educación.jsola@ua.es

Fecha de recepción: enero de 2018

Fecha de aceptación: marzo de 2018

RESUMEN

La mejora de la convivencia escolar preocupa mucho a las comunidades educativas, siendo una de sus prioridades. El objetivo de este trabajo es doble: por un lado, profundizar en la realidad de los docentes respecto a los problemas que afrontan en las aulas; por otro, analizar en qué medida la axiología forma parte de la realidad de los docentes como método para optimizar el clima de convivencia en el aula. La metodología de estudio elegida ha sido analítico-descriptiva de carácter transversal y las técnicas de medición utilizadas de corte cuantitativo. La muestra la componen 282 docentes de los Institutos de Educación Secundaria de la Comunidad Valenciana. Entre los resultados más importantes destacamos que la mayoría 
de los docentes están de acuerdo en la importancia que tienen la educación y la formación permanente en valores para transmitirla a sus alumnos y mejorar el clima en el aula.

Palabras clave: convivencia escolar; valores en educación; profesores; clima escolar.

\section{SUMMARY}

School coexistence, as one of the main objectives for the educational community, is a matter of big concern for the educational communities, being one of its main priorities. The objective of this book is double: on the one hand, to deepen the reality of teachers regarding the problems they face in the classroom; on the other hand, to analyze to what extent the axiology is a part of the reality of teachers as a method to optimize the climate of coexistence in the classroom. The chosen methodology of study has been cross-sectional, analytical-descriptive. The measurement techniques used have been quantitative. The sample is made up of 282 teachers from Secondary Education Institutes of the Valencian Community. Amongst the main results found we highlight that most teachers agree on the importance of education and permanent training in values to transmit it to their pupils and improve classroom climate.

Key words: school coexistence; values in education; teachers; school climate.

\section{SOMMAIRE}

L'amélioration de la coexistence scolaire est un sujet de grande préoccupation pour les communautés éducatives, étant l'une de leurs priorités. L'objectif de ce travail est double: d'une part, approfondir la réalité des enseignants face aux problèmes auxquels ils sont confrontés dans les salles de classe; d'autre part, d'analyser dans quelle mesure l'axiologie fait partie de la réalité des enseignants comme une méthode pour optimiser le climat de coexistence dans la salle de classe. La méthodologie d'étude retenue a été analytique-descriptive du caractère transversal et des techniques de mesure utilisées pour la coupe quantitative. L'échantillon est composé de 282 enseignants des instituts d'enseignement secondaire de la Communauté valencienne. Parmi les résultats les plus importants, nous soulignons que la plupart des enseignants sont d'accord sur l'importance de l'éducation et de la formation continue sur les valeurs pour les transmettre à leurs élèves et améliorer le climat de la classe.

Mots clés: la cohabitation dans le cadre scolaire; les valeurs dans l'éducation; les enseignants; climat scolaire. 


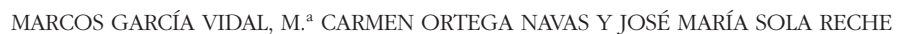

\section{INTRODUCCIÓN}

Si algo caracteriza a la sociedad actual es su flexibilidad, su pluralidad y sus vertiginosos cambios. Cambios que, sin duda, abren infinidad de oportunidades, pero solamente en la medida en que desarrollemos las competencias clave que nos permitan abordar y resolver adecuadamente los nuevos desafíos que también nos presentan (Colom y Cubero, 2001; García, 2003; López-Jurado, 2011). Entre estos retos cabría destacar: a) La ruptura con creencias, valores y costumbres hasta ahora incuestionables; b) El incremento de la diversidad étnica dentro de nuestras fronteras, generadora de multiculturalismo; c) Nuestra inmersión en la era de la imagen; d) El auge de las tecnologías de la información y la influencia de los medios de comunicación; e) Los nuevos estilos de trabajo, así como los nuevos escenarios laborales; f) La homogenización cultural inducida por la globalización (paradójicamente junto al multiculturalismo); g) El aumento de la violencia escolar, entre otras.

Ante este panorama al que nos enfrentamos, la educación en valores constituye, hoy, más que nunca, una necesidad ineludible (Ibáñez-Martín, 2013; Higgins, 2010; Escámez y Morales, 2007; Peiró, 2009, 2015; Llopis y Ballester, 2001; Ortega, 1996; Quintana, 1992; Sarabia, 1992; Vilar, 1991; Elexpuru y Medrano, 2002), como valiosa herramienta de adaptación a los cambios. Necesitamos, por este motivo, docentes plenamente conscientes de la importancia de los valores que transmiten, centros comprometidos con la enseñanza de estos valores, y discentes receptivos a adquirirlos, si queremos que la convivencia pacífica a la que aspiramos se materialice como real.

En palabras de Díez y Gonzales (1998, 6):

Los valores son como la piedra de toque para alcanzar una personalidad íntegra y bien formada. La pre-adolescencia es una etapa clave para la educación en valores, para asimilarlos y vivirlos [...]. Un centro educativo debe educar para la vida, haciendo que los futuros adultos distingan el bien del mal, afronten situaciones con coraje y busquen soluciones. De ahí que la educación en valores [...] no ha de entenderse como una serie de lecciones magistrales, sino que debe informar toda la vida del aula.

El informe elaborado para la UNESCO por la Comisión Internacional sobre Educación para el siglo xxI (Delors et al., 1996) propone una serie de valores que consideran claves para construir una ética a nivel mundial: a) la comprensión y la tolerancia en relación con las diferencias y el pluralismo cultural; b) la solicitud hacia el otro; c) el espíritu de solidaridad; d) el espíritu de empresa; e) la creatividad; f) el respeto por la igualdad entre los sexos; g) el espíritu abierto al cambio; h) el sentido de responsabilidad en la protección del medio ambiente y el desarrollo sostenible.

Entendemos que educar en valores supone desarrollar y fortalecer la conciencia y el espíritu crítico a fin de que la voluntad de la persona se ejecute mediante criterios sólidos, no de modo aleatorio o llevados por una emocionalidad 
momentánea. Por lo tanto, una persona con una buena formación en valores es aquella que elige y actúa libremente, considerando aquellos principios, normas y responsabilidades que le permitirán comportarse de manera respetuosa, solidaria y justa con los demás y consigo misma.

La educación en valores para la optimización de la convivencia escolar es, por lo tanto, fundamental para establecer unas relaciones interpersonales positivas entre los miembros de la comunidad educativa y propiciar un buen clima escolar (Peiró, 2015). Poulin, Beaumont, Blaya y Frenette (2015) aclaran, a este respecto, que la noción de clima se refiere, en particular, a los sentimientos de seguridad y justicia que prevalecen en un determinado centro educativo. A su vez, un buen clima escolar tiene como resultado la mejora del proceso de enseñanzaaprendizaje, influyendo positivamente en el rendimiento tanto de docentes como de estudiantes.

Del mismo modo, la calidad de las relaciones interpersonales, el apoyo mutuo, la cooperación y la participación de los estudiantes son considerados como factores importantes tanto en la calidad de la escuela en general (Woolley y Bowen, 2007), como en el rendimiento y desarrollo de competencias personales, sociales y profesionales que redundan en beneficio de toda la sociedad (Brookover, Schweitzer, Schneider, Beady, Flood y WisenBaker, 1978; Ponce y Sarmiento, 2017). Por todo ello consideramos importante analizar, en mayor detalle, cuáles son esos componentes concretos del clima escolar que promueven tanto el éxito académico como una baja incidencia de violencia escolar.

Según el informe TALIS de la OCDE de 2013, en nuestro país, la mayoría de docentes asegura sentirse bastante eficiente en lo que se refiere a controlar el mal comportamiento en el aula (81,5\%), dejar claras a los alumnos sus expectativas sobre el comportamiento admisible $(90,1 \%)$ o conseguir que sus alumnos cumplan las normas $(83,8 \%)$. Sin embargo, esta percepción decae extraordinariamente cuando se trata de calmar un ambiente bullicioso. De hecho, en los últimos años no ha dejado de incrementarse la preocupación por la dinámica que se produce dentro de las aulas. Haciéndose eco de ello, Pérez (2008, 24) aporta una clasificación de comportamientos que pueden ayudar al educador a identificar a los alumnos implicados en algún tipo de conflicto. Conductas interruptoras: alteran la tranquilidad necesaria del aula; conductas indisciplinadas: desacatos al reglamento del centro. Quien las realiza no tiene necesariamente la intención de molestar. Suelen ser conductas aprendidas a través de la socialización primaria; desinterés académico: rechazo al aprendizaje escolar, que se manifiesta a través de conductas como llegar tarde a clase, no prestar atención al profesor, etc.; conductas antisociales: atentan contra la integridad física o psíquica de los demás. Es frecuente que este tipo de sujetos procedan de familias desestructuradas o marginadas.

Ahora bien, dicho esto, Peiró (2009) matiza el hecho de que las conductas más graves no están muy extendidas en nuestros centros educativos, en los cuales los problemas suelen ser más de tipo «indisciplina» que de violencia. Lo que sí se constata, en cambio, con frecuencia, es la presencia del binomio indisciplina-violencia. 
Lo mismo opina Olweus (2005), para quien el acoso con violencia es solo una pequeña parte de los problemas de conducta en las escuelas, siendo la violencia escolar y las situaciones de bullying sin violencia mucho más frecuentes.

Peiró (2015), en su obra La espiral de la violencia escolar, delimita las cuatro fases que conducen, formando un espiral ascendente, hacia la cima de la violencia escolar. Entre cada una de estas fases se sitúa un conflicto y, en la medida en que este no es positivamente resuelto, la situación se enrarece y produce un empeoramiento del clima. El primero es la inatención. Se manifiesta cuando el alumno se distrae por cualquier medio y no presta atención a las explicaciones del profesor. A continuación se da la interrupción, concretada mediante acciones que rompen el hilo de la tarea académica, sobre todo cuando el docente explica contenidos. Un tercer nivel lo configura la indisciplina educacional, configurada por acciones $\mathrm{u}$ omisiones que dañan la convivencia en el aula. En el último escalón se encuentra la violencia educacional, que se refiere al conjunto de acciones u omisiones que hieren la dignidad de la persona. Puesto que, de acuerdo con este esquema, de un grado se asciende al siguiente, hay que tener en cuenta que, aunque no toda indisciplina implica agresión, sí puede suponer un paso más hasta los problemas de convivencia escolar.

Etxeberría, Esteve y Jordán (2001) consideran que en muchas ocasiones hemos ido perdiendo matices y delimitando de manera errónea lo relativo a la convivencia en la escuela. Empezamos por ceñirnos exclusivamente a los problemas de los alumnos (reducción) y de ahí pasamos a admitir que todos ellos pueden ser etiquetados como actores de violencia escolar (inflación). La imprecisión en el uso de la terminología suele provocar que el conflicto se valore negativamente, confundiéndose a menudo con violencia. Sin embargo, pedagógicamente hablando, nos consta que si el conflicto se halla en una fase inicial es aún aprovechable para desarrollar la conciencia moral (Peiró, 2012).

Además, queremos destacar que, a nivel estatal, en el año 2007, se creó en España el Observatorio Estatal de la Convivencia Escolar, como órgano de asesoramiento, análisis y difusión de información, así como una propuesta de medidas que favorezcan la convivencia escolar. No obstante, el Ministerio de Educación, del que depende este Observatorio, no tiene datos actualizados de incidencia del acoso escolar en las aulas españolas, desde 2010. De los resultados de este último informe podemos destacar que el principal obstáculo para la convivencia escolar que destaca el profesorado es "la falta de disciplina en las familias", representado por un $85 \%$; el segundo, con un $77,2 \%$, «la falta de implicación de las familias»; el tercero, con un 69,4\%, la "falta de apoyo por parte de la administración"; el cuarto, con un $69 \%$, la "legislación educativa que no permite actuar de forma adecuada»; y el quinto, con un 67\%, "la ineficacia educativa de las sanciones empleadas para corregir las transgresiones». De estos datos, podemos ya intuir una falta de transmisión de valores en la socialización primaria (ámbito familiar), situación que se verá agravada después (socialización secundaria) si los docentes no están capacitados para educar en valores. 
La última edición del informe del sindicato de profesorado ANPE, presentada en noviembre de 2017, alertaba del aumento de un 15\% de los casos de violencia contra este colectivo en el curso 2016-2017 respecto al anterior. En concreto, se cuadruplicaron las agresiones físicas y amenazas de alumnos a sus profesores.

En la última memoria anual sobre convivencia escolar en la Comunidad Valenciana, se constata cómo se han duplicado en dos años las incidencias, pasando de 1.880 en 2013-2014 a 3.414 en 2015-2016. El espectro de casos es muy variado, aunque destacan especialmente las peleas y agresiones entre el alumnado (32,01\%), las amenazas verbales al profesorado (21\%) o los insultos y las amenazas entre los escolares (16,22\%) (Generalitat Valenciana, 2017). Como afirman Marina, Rodríguez de Castro y Lorente $(2015,20)$ «durante mucho tiempo se ha venido pensado que los problemas de conducta se resolvían desarrollando destrezas psicológicas, pero poco a poco empieza a abrirse paso la idea de que son necesarios, además, valores éticos». Es preciso, por lo tanto, realizar un ejercicio consciente, planteándonos el sentido ético y moral de la educación en la actualidad.

Rossini y Peiró (2015) proponen, como prevención a estas conductas, que las prácticas didácticas se planteen con relación a una serie de criterios axiológicos que sirvan de base a los contenidos puramente teóricos, teniendo presente que estos criterios deben ser abiertos y susceptibles de cambio conforme a las circunstancias. Desde un punto de vista humanista, la persona se considera una unidad dinámica en desarrollo, integrada por diferentes áreas: biológica, psicológica, social y espiritual (Bosello, 1999). La educación en valores debe, por lo tanto, atender a todas estas facetas, porque todo lo que uno hace, piensa, dice y siente no es sino un reflejo de aquellos valores que ha interiorizado a lo largo de su vida.

Nadie duda de que la labor del profesorado en el aula es uno de los elementos que más incide en el proceso de aprendizaje de los alumnos, pero lo que suele obviarse es que su influencia no se circunscribe únicamente al ámbito académico. Los profesores son, asimismo, líderes emocionales, y de su habilidad para identificar, comprender y regular sus propias emociones en el aula se desprenderá un mejor o peor equilibrio emocional para el sistema del aula en su conjunto (Ortega, 2014).

Pestana (2003) incide en el hecho de que las acciones de los docentes suelen inclinarse preferentemente al desarrollo de objetivos de tipo académico, obviando el cultivo explícito de actitudes positivas y, en general, de valores. Una vez más se hace aquí hincapié -no nos cansaremos de insistir en este punto- en la común presunción de que tanto las actitudes como los valores se formarán de modo espontáneo y automático mediante la enseñanza de conocimientos.

Uno de los retos más significativos a los que se enfrenta cada profesor es, por el contrario, el de desarrollar cualidades éticas en sus alumnos. Carr (2003, 2005, 2006) llama la atención sobre el modo en que los valores penetran en toda la práctica de la enseñanza y, a su vez, redundan en una enseñanza de calidad.

Y es que, más allá de la competencia técnica necesaria, la enseñanza eficaz es guiada por la aplicación concreta de valores, lo que requiere de los docentes una 
especial capacidad en las relaciones interpersonales con sus alumnos. Esto significa que los valores personales, y las prácticas que de ellos se derivan, desempeñan un papel clave en la enseñanza. Como apunta Schön (1992), el docente debe saber, saber hacer, saber hacer moralmente bien y saber reflexionar sobre su acción. Promover ciertos valores en el educando exige por parte del educador un compromiso personal. Pues en el ámbito práctico no es posible encauzar eficazmente a nadie en un sentido determinado, ni dar a entender el significado profundo de los conceptos, si quien habla no está vitalmente empeñado en lo que promueve (Ibáñez-Martín, 1992).

A este respecto, Day (2012) añade que la pasión por educar no consiste solo en manifestar entusiasmo, sino también en llevarla a la práctica de manera inteligente, fundada en unos principios y orientada en unos valores. Los docentes eficaces se caracterizan precisamente por eso, por su pasión. Pasión por su asignatura, pasión por sus alumnos y la creencia apasionada de que su forma de enseñar puede influir positivamente en la vida de sus alumnos, tanto en el momento mismo en que se produce como días, semanas, meses, e incluso años más tarde. Esta pasión se relaciona, además, con el compromiso y con la esperanza, que, se ha demostrado, son características clave de la eficacia en la enseñanza. No es, por lo tanto, caer en el sentimentalismo reconocer que el propósito moral del docente es una parte esencial de la eficacia de su labor y un aspecto fundamental en la convivencia escolar (Day y Gu, 2010).

Con relación a este contexto teórico, y a la temática que nos ocupa, se nos plantean dos cuestiones a las que consideramos que sería oportuno responder: ¿Qué situaciones son las que alteran principalmente el trabajo de los profesores? ¿Qué valores transmiten los docentes en sus centros educativos? ¿Qué importancia le dan los docentes a la educación en valores? Tomando como base las mismas, fijamos los siguientes objetivos para nuestra investigación: profundizar en la realidad de los docentes respecto a los problemas que afrontan en las aulas; y, en estrecha relación, analizar en qué medida y de qué manera la axiología forma parte del trabajo de los docentes.

\section{MÉTODO}

\subsection{Muestra}

La muestra de nuestro estudio se sitúa en el conjunto de los Institutos de Enseñanza Secundaria de la Comunidad Valenciana (IES). La población viene configurada por los docentes de los IES pertenecientes a dicha Comunidad que, en el curso académico 2013/2014, ascendía a un total de 25.252 personas (IVE, 2016).

Finalmente, tras realizar una selección no aleatoria, voluntaria, de la muestra en diferentes IES de la Comunidad (Alicante: 187 centros $=66,3 \%$; Valencia: 72 centros $=25,5 \%$; y Castellón: $23=8,2 \%$ ), se obtuvo una muestra real de 282 personas que participaron en la investigación. De los encuestados, el 56\% fueron mujeres y 
el 44\% hombres, siendo sus frecuencias de 158 y 124 respectivamente. En cuanto a los años de experiencia docente, conforme a los datos obtenidos se desprende, se situaron en los siguientes intervalos: 0-5 años: 10 docentes (3,5\%); 6-10 años: 36 docentes (12,8\%); 11-15 años: 52 docentes (18,4\%); 16-20 años: 51 docentes (18,1\%); 21-25 años: 41 docentes (14,5\%); 26-30 años: 68 docentes (24,1\%); más de 30 años: 24 docentes $(8,5 \%)$.

Respecto al tamaño de la muestra y su representatividad como características que garanticen la confiabilidad de los datos recabados, hemos seguido una fórmula para poblaciones finitas. Con un tamaño de muestra $n=25.252$ respecto a la población del profesorado y según la seguridad planteada $=95 \%$; la precisión $=3 \%$; y la proporción esperada $=$ próxima al 5\%, la muestra real productora de datos (282) resulta estar por encima del tamaño de la muestra estadística, confirmando así su grado de adecuación y significación respecto a la población.

\subsection{Instrumento}

Llevados por la necesidad de obtener información de forma sistemática y ordenada de las variables que intervienen en nuestra investigación, decidimos optar, como elemento de carácter cuantitativo, por una de las técnicas más utilizadas en la investigación educativa: el cuestionario (Fox, 1981; Kerlinger, 1981; Kemmis y McTaggart, 1988; Cohen y Manion, 1990). Nos decantamos por esta técnica porque, entre sus ventajas, destaca que, mediante la utilización de datos numéricos, se obtiene una visión rápida, general y global que permite conocer lo que hacen, opinan o piensan los encuestados (Ugalde y Balbastre, 2013; López-Barajas, 2015).

Para nuestro estudio hemos elegido un diseño de encuesta de elaboración propia (Valores y convivencia escolar) tipo Likert (Llauradó, 2014; Sánchez et al., 1993), en un rango de 1 a 5, y en correspondencia con las siguientes categorías: 1 = Nunca; 2 = Casi nunca; $3=$ A veces $; 4=$ Casi siempre $;=$ Siempre. En la elaboración de esta encuesta nos decidimos por crear nuestra propia escala de valores. Para ello se seleccionaron valores que un grupo de expertos (profesores de la Universidad de Alicante) y alumnos de la Facultad de Educación de la Universidad de Alicante han trabajado conjuntamente (Peiró, 2005-2009).

Para la obtención del índice de fiabilidad del instrumento, se aplicó el test Alfa de Cronbach, obteniéndose un valor de ,977. Posteriormente, se calculó el Alfa de Cronbach en los distintos bloques del cuestionario, a saber: 1. Convivencia escolar y clima de enseñanza-aprendizaje; 2. Actuación del docente frente al conflicto; 3. Convergencia de los valores en el proyecto educativo de centro (PEC); 4. Técnicas y herramientas axiológicas para la mejora de la convivencia escolar, y 5. Evaluación axiológica.

El primer bloque es el referido a la convivencia escolar y al clima de enseñanza-aprendizaje. Las cuestiones que se plantean en este bloque son:

Cuestión 1: Cuando se producen conflictos en su centro de trabajo ¿entre qué miembros de la comunidad educativa son más frecuentes? 
Cuestión 2: De entre las siguientes situaciones indique, en cada caso, la frecuencia con la que Vd. las encuentra en el desempeño de su trabajo.

Cuestión 3: ¿Cómo se siente Vd. respecto al clima reinante en su centro de trabajo?

Siendo el Alpha de Crombach en este bloque igual a ,8452.

El segundo bloque trata la actuación docente frente al conflicto, y plantea las siguientes preguntas:

Cuestión 4: ¿Cómo actúa Vd. habitualmente para atajar los problemas de convivencia en el aula?

Cuestión 5: ¿Hasta qué punto considera Vd. que la educación en valores es asunto de su competencia?

Cuestión 6: ¿Qué valores, de entre los siguientes, considera Vd. que trasmite en sus clases?

Siendo el Alpha de Crombach en este bloque igual a ,8623.

El tercer bloque explora la convergencia de los valores en el proyecto educativo de centro (PEC), para lo cual las preguntas vertidas en el cuestionario son:

Cuestión 7: ¿Considera Vd. importantes los valores transmitidos en el Proyecto Educativo de Centro para la mejora de la convivencia escolar?

Cuestión 8: ¿Considera Vd. que los valores influyen en un buen clima escolar?

Cuestión 9: ¿Cree Vd. posible modificar los hábitos de comportamiento desadaptado de determinados alumnos mediante una educación en valores?

Siendo el Alpha de Crombach en este bloque ,6843.

El cuarto bloque es el referido a las técnicas y herramientas axiológicas para la mejora de la convivencia escolar. Las preguntas que se plantean en el cuestionario son:

Cuestión 10: De los siguientes recursos ¿cuáles utiliza en sus clases para fomentar un clima positivo?

Cuestión 11: ¿Cómo elabora las técnicas que utiliza para la educación en valores?

Cuestión 12: ¿Considera Vd. necesario realizar formación docente en educación en valores a fin de mejorar la convivencia escolar?

Siendo el Alpha de Crombach en este bloque igual a ,9072.

El quinto bloque se ocupa de la evaluación axiológica, y plantea las siguientes cuestiones:

Cuestión 13: ¿Cómo determina Vd. los valores que poseen sus alumnos?

Cuestión 14: ¿Mediante qué instrumentos evalúa Vd. los valores presentes en sus alumnos?

Cuestión 15: Señale la periodicidad con que evalúa Vd. los valores presentes en sus alumnos.

Siendo el Alpha de Crombach en este bloque ,8401. 
TABLA 1

ÍNDICE DE FIABILIDAD DEL CUESTIONARIO

\begin{tabular}{|c|c|c|}
\hline Bloques & Cuestiones & Crombach \\
\hline 1 & $1,2,3$ &, 8452 \\
\hline 2 & $4,5,6$ &, 8623 \\
\hline 3 & $7,8,9$ &, 6843 \\
\hline 4 & $10,11,12$ &, 9072 \\
\hline 5 & $13,14,15$ &, 8401 \\
\hline
\end{tabular}

FUENTE: Elaboración propia.

\subsection{Diseño}

Mediante la reflexión fenomenológica se delineó la problemática de la dimensión social de la docencia (Fermoso, 1989; Pérez, 2004). Es importante destacar que nuestro estudio analítico-descriptivo tiene un carácter transversal. Este modelo se define como el estudio de un grupo de sujetos en un corte puntual en el tiempo, del cual se obtienen medidas a tratar. El proceso de recogida de los datos se realizó por medio de las nuevas tecnologías, concretamente a través del correo electrónico. El cuestionario elaborado se envió, de modo escalonado, a todos los directores de centros de educación secundaria (tanto públicos como privados) de la Comunidad Valenciana. Junto con el cuestionario, se envió una carta de presentación de la investigación, con la solicitud de que fuesen los propios directores los que colaborasen en la distribución, entre el profesorado de sus centros, del instrumento de medición. Para la recogida de los datos, los docentes contestaron el cuestionario a través de la aplicación Google Forms, donde no había tiempo delimitado en la respuesta del instrumento de medida.

Las técnicas de medición utilizadas fueron de corte cuantitativo. Dado el carácter descriptivo de este trabajo, el diseño de investigación se centró en el estudio de las medias, las frecuencias y las desviaciones estándar de los datos obtenidos. Realizándose una inferencia estadística a través de la prueba Chi-Cuadrado, el nivel de confianza elegido es del 95\% $(\alpha=0,05)$, cruzando aquellas variables que dan respuesta a las cuestiones de investigación planteadas en el estudio. Finalmente se llevó a cabo el estudio de diferencias de medias (T-Student) de aquellos valores que en el Chi-cuadrado $\chi^{2}$ presentaban dependencia de la variable sexo. Para el análisis de los datos cuantitativos obtenidos en los cuestionarios se ha utilizado el paquete estadístico Statistical Package for the Social Sciencies (versión 21.0 para Windows). 


\section{ANÁLISIS}

De acuerdo con los objetivos fijados en nuestra investigación, se llevó cabo, en primer término, un análisis descriptivo a través del estudio de la media y la desviación estándar en las respuestas. En segundo lugar se realizó un análisis bivariado de las variables «sexo» $\mathrm{y}$ "valores trasmitidos por los docentes», mediante la prueba de $\chi^{2}$. Finalmente se realizó la prueba de muestras independientes T-student para aquellos valores dependientes del estudio $\chi^{2}$.

TABLA 2

SitUaCiOnES QUE ALTERAN EL TRABAJO DOCENTE

\begin{tabular}{|c|c|c|c|c|c|c|c|c|}
\hline \multirow{2}{*}{$\begin{array}{c}\text { Adicción a } \\
\text { estupefacientes }\end{array}$} & Media & Desviación & \multirow{2}{*}{ Agresiones } & Media & Desviación & \multirow{2}{*}{$\begin{array}{l}\text { Charlar en } \\
\text { clase, uso } \\
\text { de móviles }\end{array}$} & Media & Desviación \\
\hline & \multicolumn{2}{|l|}{2,1064} & & 2,4823 & ,90944 & & \multicolumn{2}{|l|}{4,1915} \\
\hline \multirow{2}{*}{$\begin{array}{c}\text { Discriminación } \\
\text { racial, } \\
\text { religiosa, etc. }\end{array}$} & Media & Desviación & \multirow{2}{*}{$\begin{array}{l}\text { Abandono } \\
\text { de estudios }\end{array}$} & Media & Desviación & \multirow{2}{*}{$\begin{array}{c}\text { Falsificación } \\
\text { de } \\
\text { documentos }\end{array}$} & Media & Desviación \\
\hline & 2,4610 & ,88497 & & 3,1879 & ,89887 & & 1,8972 &, 73076 \\
\hline \multirow{2}{*}{ Insulto } & Media & Desviación & \multirow{2}{*}{$\begin{array}{l}\text { Fugarse } \\
\text { las clases }\end{array}$} & Media & Desviación & \multirow{2}{*}{$\begin{array}{l}\text { Retraso en } \\
\text { el inicio de } \\
\text { las clases }\end{array}$} & Media & Desviación \\
\hline & 3,3227 & ,96861 & & 2,9823 & ,97095 & & 3,4468 & ,99411 \\
\hline \multirow{2}{*}{ Robos } & Media & Desviación & \multirow{2}{*}{ Vandalismo } & Media & Desviación & \multirow{2}{*}{ Xenofobia } & Media & Desviación \\
\hline & 2,1879 & ,78925 & & 2,2837 & ,89940 & & 2,1596 & ,88446 \\
\hline \multirow{2}{*}{$\begin{array}{l}\text { Presiones } \\
\text { de grupos a } \\
\text { chicos/as }\end{array}$} & Media & Desviación & \multirow{2}{*}{$\begin{array}{l}\text { Abuso } \\
\text { sexual }\end{array}$} & Media & Desviación & & Media & Desviación \\
\hline & 2,4326 & ,91102 & & 1,3085 &, 54072 & & & \\
\hline
\end{tabular}

FUENTE: Elaboración propia.

Respecto al estudio de las medias representadas en la Tabla 3, aquellas cuyas variables obtienen valores más elevados son: «charlar en clase»/«uso del móvil» (4,1915); «retraso en el inicio de las clases» $(3,4468)$; «insulto» $(3,3227)$, y «abandono de estudios» $(3,1879)$.

Se encuentran también muchas variables agrupadas bajo la respuesta casi nunca, entre las que destacan: "agresiones» $(2,4823)$; "discriminación racial y religiosa» (2,4610); "vandalismo» (2,2837); "presiones de grupos a chicos» $(2,4326)$; "adicción a estupefacientes» $(2,1064)$; «robos» $(2,1879)$, y "xenofobia» $(2,1596)$.

Las dos variables que obtienen mayor puntuación en la respuesta nunca son el «abuso sexual» $(1,3085)$ y la "falsificación de documentos» $(1,8972)$. 
TABLA 3

VALORES QUE TRASNMITEN LOS DOCENTES

\begin{tabular}{|c|c|c|c|c|c|c|c|c|}
\hline \multirow{2}{*}{ Obediencia } & Media & Desviación & \multirow{2}{*}{ Puntualidad } & Media & Desviación & \multirow{2}{*}{ Orden } & Media & Desviación \\
\hline & 3,6383 & ,99305 & & 4,2660 & ,88292 & & 4,2553 & ,81275 \\
\hline \multirow{2}{*}{ Veracidad } & Media & Desviación & \multirow{2}{*}{ Cuidado } & Media & Desviación & \multirow{2}{*}{ Respeto } & Media & Desviación \\
\hline & 4,6525 &, 57820 & & 4,3511 &, 71647 & & 4,8262 & ,45539 \\
\hline \multirow{2}{*}{ Armonía } & Media & Desviación & \multirow{2}{*}{ Sinceridad } & Media & Desviación & \multirow{2}{*}{ Fortaleza } & Media & Desviación \\
\hline & 4,2340 & 82779 & & 4,5993 & 65815 & & 3,8475 & 1,01316 \\
\hline \multirow{2}{*}{ Optimismo } & Media & Desviación & \multirow{2}{*}{ Amistad } & Media & Desviación & \multirow{2}{*}{ Audacia } & Media & Desviación \\
\hline & 4,3050 &, 79090 & & 4,1099 & ,88802 & & 3,3830 & ,99936 \\
\hline \multirow{2}{*}{ Sencillez } & Media & Desviación & \multirow{2}{*}{ Templanza } & Media & Desviación & \multirow{2}{*}{$\begin{array}{c}\text { Ser } \\
\text { estudioso }\end{array}$} & Media & Desviación \\
\hline & 3,9007 & ,99683 & & 3,8688 & ,94727 & & 4,1773 & ,82904 \\
\hline \multirow{2}{*}{ Justicia } & Media & Desviación & \multirow{2}{*}{ Sociabilidad } & Media & Desviación & \multirow{2}{*}{ Paciencia } & Media & Desviación \\
\hline & 4,5177 &, 71688 & & 4,2695 &, 86349 & & 4,2447 &, 83542 \\
\hline \multirow{2}{*}{ Pudor } & Media & Desviación & \multirow{2}{*}{ Sobriedad } & Media & Desviación & \multirow{2}{*}{ Humildad } & Media & Desviación \\
\hline & 3,4326 & 1,2126 & & 3,3440 & 1,1154 & & 4,0709 & ,94432 \\
\hline
\end{tabular}

FUENTE: Elaboración propia.

La Tabla 3 representa los valores que los docentes transmiten mientras desarrollan su labor. Como puede comprobarse, todos los valores puntúan de media por encima de la opción a veces. Los valores en los que encontramos medias más elevadas se agrupan en la opción casi siempre, rozando valores de siempre: "veracidad" (4,6525); "cuidado» (4,3511); «respeto" (4,8262); «sinceridad» (4,5993); "optimismo» $(4,3050)$; y «usticia» $(4,5177)$.

Los valores que alcanzan medias intermedias, y que, por lo tanto, se sitúan en los intervalos establecidos entre a veces y siempre, son los siguientes: "puntualidad" (4,2660); "orden" (4,2553); "armonía» (4,2340); "amistad" (4,1099); "ser estudioso» (4,1773); "sociabilidad" (4,2695); y "paciencia» (4,2447).

Los valores que obtuvieron las puntuaciones más bajas fueron: "obediencia" (3,6383); "fortaleza" (3,8475); "audacia» (3,3830); "sencillez" (3,9007); "templanza» $(3,8668)$; "pudor» $(3,4326)$; y "Sobriedad" $(3,3440)$. 
MARCOS GARCÍA VIDAL, M. ${ }^{a}$ CARMEN ORTEGA NAVAS Y JOSÉ MARÍA SOLA RECHE

LA IMPORTANCIA DE LOS VALORES TRANSMITIDOS POR EL PROFESORADO DE SECUNDARIA...

TABLA 4

Estudio Chi-CuAdrado (NIVEL DE CONFIANZA ELEGIDO DEL 95\%, A= 0,05), RELACIÓN SEXO Y VALORES QUE TRANSMITEN LOS DOCENTES

\begin{tabular}{|c|c|c|c|}
\hline \multirow[b]{2}{*}{ Obediencia } & Value & Df & Asymp. Sig. (2-sided) \\
\hline & \multicolumn{3}{|c|}{$\begin{array}{l}\text { a. } 2 \text { cells }(20,0 \%) \text { have expected count less than } 5 \text {. The minimum expected } \\
\text { count is } 1,32 \text {. }\end{array}$} \\
\hline Puntualidad & \multicolumn{3}{|c|}{$\begin{array}{l}\text { a. } 2 \text { cells }(20,0 \%) \text { have expected count less than } 5 \text {. The minimum expected } \\
\text { count is }, 44 \text {. }\end{array}$} \\
\hline Orden & \multicolumn{3}{|c|}{$\begin{array}{l}\quad 6,956^{\mathrm{a}} \\
\begin{array}{l}3 \\
\text { a. } 1 \text { cells }(12,5 \%)\end{array} \\
\text { count is } 3,96 \text {. }\end{array}$} \\
\hline Veracidad & \multicolumn{3}{|c|}{$\begin{array}{l}9,700^{\mathrm{a}} \\
\begin{array}{l}2 \\
\text { a. } 0 \text { cells }(, 0 \%)\end{array} \text { have expected count less than } 5 \text {. The minimum expected } \\
\text { count is } 6,60\end{array}$} \\
\hline Cuidado & \multicolumn{3}{|c|}{$\begin{array}{l}9,597^{\mathrm{a}} \\
\text { a. } 4 \text { cells }(40,0 \%) \text { have expected count less than } 5 \text {. The minimum expected } \\
\text { count is }, 44 .\end{array}$} \\
\hline Respeto & \multicolumn{3}{|c|}{$\begin{array}{l}13,560^{\mathrm{a}} \\
\begin{array}{l}2 \\
\text { a. } 2 \text { cells }(33,3 \%)\end{array} \text { have expected count less than } 5 \text {. The minimum expected } \\
\text { count is } 1,76 \text {. }\end{array}$} \\
\hline Armonía & \multicolumn{3}{|c|}{$\begin{array}{l}14,650^{a} \\
\text { a. } 4 \text { cells }(40,0 \%) \text { have expected count less than } 5 \text {. The minimum expected } \\
\text { count is } 1,32\end{array}$} \\
\hline Sinceridad & \multicolumn{3}{|c|}{$\begin{array}{l}\qquad, 625^{\mathrm{a}} \\
\begin{array}{l}3 \\
\text { a. } 2 \text { cells }(25,0 \%)\end{array} \\
\text { count is } 2,20 \text {. }\end{array}$} \\
\hline Fortaleza & \multicolumn{3}{|c|}{$\begin{array}{l}13,302^{\mathrm{a}} \quad 4 \quad, 010 \\
\text { a. } 2 \text { cells }(20,0 \%) \text { have expected count less than } 5 \text {. The minimum expected } \\
\text { count is } 1,76 .\end{array}$} \\
\hline Optimismo & \multicolumn{3}{|c|}{$\begin{array}{l}4,173^{\mathrm{a}} \\
\begin{array}{l}3 \\
\text { a. } 2 \text { cells }(25,0 \%)\end{array} \\
\text { count is } 1,76\end{array}$} \\
\hline Amistad & \multicolumn{3}{|c|}{$\begin{array}{l}\text { a. } 1 \text { cells }(12,5 \%) \text { have expected count less than } 5 \text {. The minimum expected } \\
\text { count is } 4,84\end{array}$} \\
\hline Audacia & \multicolumn{3}{|c|}{$\begin{array}{l}\text { a. } 2 \text { cells }(20,0 \%) \text { have expected count less than } 5 \text {. The minimum expected } \\
\text { count is } 3,52\end{array}$} \\
\hline
\end{tabular}


MARCOS GARCÍA VIDAL, M. ${ }^{a}$ CARMEN ORTEGA NAVAS Y JOSÉ MARÍA SOLA RECHE LA IMPORTANCIA DE LOS VALORES TRANSMITIDOS POR EL PROFESORADO DE SECUNDARIA...

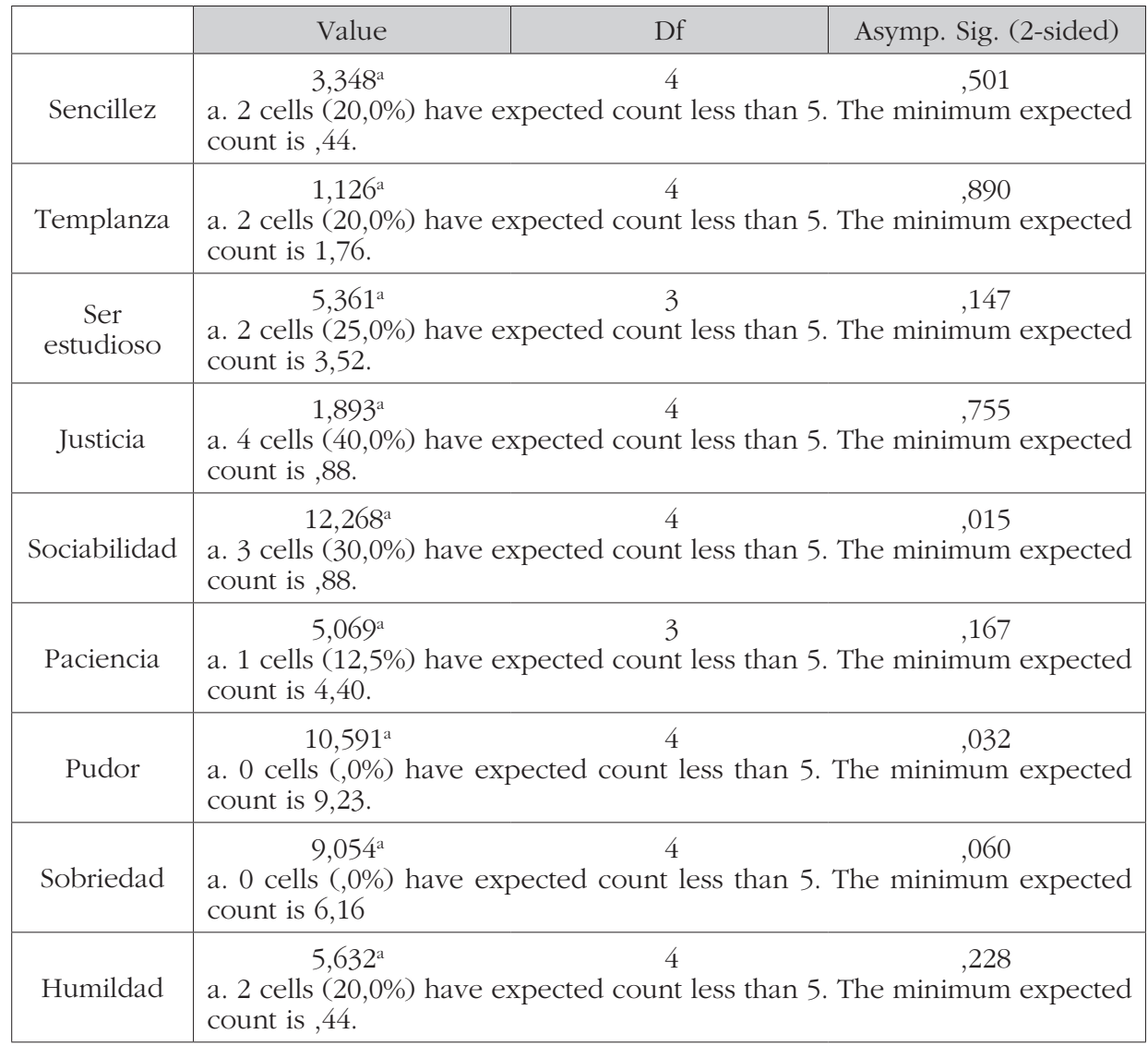

FUENTE: Elaboración propia.

En la Tabla 4, se presenta el estudio Chi-cuadrado de las variables sexo y los valores que los docentes transmiten en sus clases. Son los valores "Armonía" $\chi^{2}(\mathrm{gl}=4, \mathrm{~N}=282)=14,650, \mathrm{p}<, 005$; "Respeto" $\chi^{2}(\mathrm{gl}=2, \mathrm{~N}=282)=13,560$, $\mathrm{p}<, 005 ; \mathrm{y}$ "Audacia» $\chi^{2}(\mathrm{gl}=4, \mathrm{~N}=282)=18,159, \mathrm{p}<, 005$, aquellos que han puntuado con un índice de significación por debajo de $\alpha=0,05$, por lo que se puede concluir que existe dependencia entre la variable sexo y el valor. Dicho de otro modo, existen diferencias significativas entre los profesores y las profesoras a la hora de transmitir valores.

En cuanto a los valores "Obediencia», "Puntualidad», "Orden", "Cuidado", "Sinceridad», "Optimismo», "Amistad», "Sencillez», "Templanza», "Ser estudioso», "Justicia», "Paciencia», "Pudor", "Sobriedad" $\mathrm{y}$ "Humildad", obtuvieron un índice de significación por encima de $\alpha=0,05$, lo que indica que son independientes la variable sexo 
y el valor seleccionado. Esto muestra que, en estos casos, no existen diferencias significativas entre sexos, y que ambos trabajan estos valores por igual.

En la Tabla 5 se presentan los resultados obtenidos acerca de si los valores influyen en la convivencia. La respuesta por parte de los docentes se sitúa en una media en torno al 4,5035, situada en valores entre "casi siempre" y "siempre» del instrumento de medida. Este dato apunta a una relación significativa entre la influencia que pueden ejercer los valores y la convivencia escolar, en la subjetividad de los docentes.

TABLA 5

INFLUENCIA DE LOS VALORES EN LA CONVIVENCIA

\begin{tabular}{|c|c|c|}
\hline & Media & Desviación \\
\hline Los valores influyen en la convivencia & 4,5035 &, 84470 \\
\hline
\end{tabular}

FUENTE: Elaboración propia.

La Tabla 6, por su parte, presenta la necesidad por parte de los docentes de formación en materia axiológica. El dato muestra una media de 3,9362, situada en el "casi siempre». El análisis del dato nos lleva a pensar que los docentes pueden sentirse carentes de formación específica al respecto.

TABLA 6

NECESIDAD DE FORMACIÓN DE LOS DOCENTES EN EDUCACIÓN EN VALORES

\begin{tabular}{|c|c|c|}
\hline & Media & Desviación \\
\hline $\begin{array}{c}\text { Necesidad de formación docente en } \\
\text { materia de educación en valores }\end{array}$ & 3,9362 & 1,18239 \\
\hline
\end{tabular}

FUENTE: Elaboración propia.

\section{DisCUSIÓN Y CONCLUSIONES}

Tras el análisis de los resultados, y con la prudencia debida en cuanto a las dificultades y limitaciones que conllevan las investigaciones en el ámbito educativo, destacamos los siguientes aspectos:

Respecto a la convivencia escolar y al clima de enseñanza-aprendizaje, si hay conflictos o si el clima no es el adecuado, el docente no puede realizar bien su trabajo (Backhoff, Bouzas Riaño, Contreras, Hernández y García, 2007). De hecho, numerosos estudios coinciden en señalar las múltiples ventajas que se obtienen cuando existen ambientes saludables y positivos para la convivencia escolar 
(Romagnoli, Mena y Valdes, 2007), señalando, además, el clima escolar como clave para la existencia de un aprendizaje óptimo (Mena y Valdes, 2008).

Cabría matizar, además, que, mientras los conflictos provocados entre los alumnos parecen afectar a todo el centro educativo y, por lo tanto, a la convivencia en general, los efectos de aquellos que se producen entre alumnos y profesores suelen quedar circunscritos al nivel del aula. Estos conflictos tienen sus principales manifestaciones en retrasos en el inicio de las clases, así como en el uso indebido de móviles, y suelen tener como consecuencia la creación de un clima enrarecido en el aula (Blaya y Debarbieux, 2011; Peiró, 2005; Peiró, 2009; Peiró, 2015).

Centrándonos en el estudio de los valores que los docentes manifiestan trabajar en sus respectivos centros, queremos antes matizar que los valores son parte de las representaciones sociales de la cultura (Arellano, 2010), por lo que su análisis nos permitirá un acercamiento al clima del centro educativo a partir del significado que los profesores les den.

Respecto a los valores, los profesores muestran un elevado nivel de acuerdo, coincidiendo en señalar al respeto $(M=4,8262$; $\mathrm{SD}, 45539)$ como el valor principal que debe imperar en las aulas. Asimismo, los datos señalan que los docentes son conscientes de que, ya sea de modo explícito o implícito, ellos mismos son una fuente importante de transmisión de valores. Por otra parte, los valores que los docentes consideran transmitir en mayor medida en sus actuaciones son veracidad, respeto, cuidado, sinceridad, optimismo y justicia. Algo más en segundo plano se situarían aquellos valores como orden, puntualidad, armonía, amistad, ser estudioso, sociabilidad y paciencia.

En el estudio realizado de la dependencia del sexo respecto a los valores que transmiten los docentes no se muestran diferencias por sexo en la mayoría de los valores, lo que nos hace pensar que tanto hombres como mujeres trabajan los valores de un modo similar en las aulas. Los valores que mostraron diferencias fueron respeto, armonía y audacia, esto nos hace pensar que es necesario sistematizar los criterios axiológicos en pro de la convivencia escolar, así como en la formación de los docentes en esta área.

Si comparamos los resultados relativos a la importancia que los docentes dan a la educación en valores, con los resultados de las situaciones que alteran el trabajo docente, podemos concluir que, a mayor importancia dada por los docentes a educar en valores (Tabla 5), obtenemos mejores datos en convivencia escolar. Tal como demuestra la Tabla 3 donde las situaciones agresivas o violentas en los centros estudiados son casi inexistentes.

En materia de formación en educación en valores, se pone de manifiesto que los docentes demandan dicha formación, viéndola como útil para el desempeño de generar mayor clima en el aula, como potenciar la convivencia escolar.

A partir de las conclusiones expuestas, y con el objetivo de mejorar las herramientas docentes en materia de educación en valores, venimos a proponer las siguientes líneas de trabajo: 
a) Mejorar la formación específica de los docentes en el aspecto axiológico, bien sea a través de másteres universitarios, bien a través de cursos monográficos. Consideramos importante, en este sentido, que desde las universidades se planteen cursos específicos en materia axiológica destinados a los futuros profesores, así como formación complementaria en el desarrollo profesional docente.

b) Conocer fundamentos teóricos y metodológicos de la educación en valores. Nos parece fundamental que las cuestiones axiológicas formen parte de los fundamentos teóricos en la construcción de las unidades didácticas, así como en la organización escolar.

c) Potenciar, dentro de los centros educativos, la creación de grupos de trabajo para tratar, específicamente, de aspectos relacionados con la axiología y su uso para mejorar el clima escolar. El hecho de poder compartir experiencias por parte de los docentes no solo enriquece el trabajo de todos, sino que ayuda a no encontrarse solos frente a cuestiones tan críticas como las derivadas de la convivencia escolar.

d) Crear recursos específicos donde los docentes puedan encontrar material, técnicas, consejo y apoyo en todos aquellos temas relacionados con la educación en valores. Como sostienen Medina y Domínguez, 2015, un buen modelo tecnológico nos aporta nuevas formas de entender y desarrollar los procesos de enseñanza-aprendizaje. El renovarse en materia axiológica, profundizar en los materiales y técnicas, necesita de plataformas modernas de comunicación para actuar, incidir y cambiar los procesos sociales que se producen en los centros educativos.

e) Solicitar mayores recursos de las Administraciones Públicas para potenciar y mejorar la educación en valores.

f) Solicitar, asimismo, que las Administraciones Públicas se impliquen en la concienciación, a nivel general, de la importancia que la transmisión de valores tiene para la mejora no solo del clima escolar, sino del clima social en general.

Cuando se habla de educar en valores, suele hacerse únicamente referencia al cultivo de aquellas actitudes que facilitan el tranquilo discurrir de las clases, en detrimento de aquellos valores que permiten el desarrollo personal. Es por ello por lo que resulta fundamental programar las clases de modo más participativo, identificar con claridad los valores y antivalores, dando lugar a una comunidad de aprendizaje axiológico, y crear un espacio común para resolver problemas y compartir las perspectivas de los alumnos.

Para finalizar indicamos algunas deficiencias del estudio llevado a cabo, para destacar así la importancia de seguir profundizando y mejorando en estas cuestiones. La principal, a nuestro modo de ver, fue que la selección de la muestra se realizó a través del envío por correo electrónico de los cuestionarios a los directores de los centros para que fuesen estos quienes, a su vez, distribuyesen los 
cuestionarios a los docentes. Esto hizo que se perdiese, de algún modo, el control directo de las pruebas.

Consideramos, en cualquier caso, importante continuar con estudios como el presentado, que permitan obtener datos que faciliten la puesta en marcha de programas de prevención basados en la educación en valores y buenas prácticas entre los adolescentes. También es importante introducir a la familia (Ortega, 2014).

\section{REFEFENCIAS BIBLIOGRÁFICAS}

ANPE (2017) El defensor del profesor. Informe 2016-2017. Consultado el 22 de junio de 2018. https://eldefensordelprofesor.es/documentos-informes.

ARellano, R. (2010) La construcción cultural de los valores familia y escuela. Revista Académica de la Universidad Católica del Maule, 38, 31-42.

Backhoff, E.; Bouzas, A.; Contreras, C.; Hernández, E. y García, M. (2007) Factores escolares y aprendizaje en México. El caso de la educación. México, Instituto Nacional para la Evaluación de la Educación.

Blaya, C. y Debarbieux, É. (2011) La violencia en los colegios de enseñanza primaria: ¿̨cómo están los alumnos franceses? Revista Internacional de Investigación en Educación, 4 (8), 339-356.

Bosello, A. P. (1999) Escuela y valores: la educación moral. Madrid, cCS.

Brookover, W. B.; Schweitzer, J. H.; Schneider, J. M.; Beady, C. H.; Flood, P. K. y WisEnBAKER, J. M. (1978) Elementary school social climate and school achievement. American Educational Research Journal, 15, 301-318.

CARR, D. (2003) Moral educational implications of rival conceptions of education and the role of the teacher. Journal of Moral Education, 32, 219-232.

CARR, D. (2005) Personal and interpersonal relationships in education and teaching: A virtue ethical perspective. British Journal of Educational Studies, 53, 255-271.

CARR, D. (2006) Professional and personal values and virtues in teaching. Oxford Review of Education, 32, 2.

Cohen, L. y Manion, L. (1990) Métodos de Investigación educativa. Madrid, Editorial La Muralla.

Colom, A. J. y Cubero, L. (2001) Teoría de la Educación. Madrid, Síntesis.

DAY, C. (2012) Pasión por enseñar. La identidad personal y profesional del docente y sus valores. Madrid, Narcea.

DaY, C. y Gu, Q. (2010) The new lives of teachers. London, Routledge.

Delors, J.; Al Mufti, I.; Amagi, I.; Carneiro, R.; Chung, F.; GeremeK, B. y NazhaO, Z. (1996) Informe a la Unesco de la comisión internacional sobre la educación para el siglo XXI: La educación encierra un tesoro. Madrid, Santillana, Ediciones UNESCO.

Díez, E. y GonZÁlez, R. (1998) Infinitud humana: la grandeza de los valores. Barcelona, Editorial Praxis.

Elexpuru, I. y Medrano, C. (2002) El desarrollo de los valores en las instituciones educativas. Bilbao, Mensajero, CIDE.

Escámez, J. y Morales, S. (2007) Competencias para la convivencia en una sociedad plural. Revista Miscelánea Comillas. Revista de Ciencias Humanas y Sociales, 65 (126) 481-509. 
MARCOS GARCÍA VIDAL, M. ${ }^{a}$ CARMEN ORTEGA NAVAS Y JOSÉ MARÍA SOLA RECHE

LA IMPORTANCIA DE LOS VALORES TRANSMITIDOS POR EL PROFESORADO DE SECUNDARIA...

Etxeberría, F.; Esteve, J. M. y Jordán, J. A. (2001). La escuela y la crisis social, en Ortega, P. (coord.) Conflicto, violencia y Educación. Actas del XX Seminario Interuniversitario de Teoría de la Educación. Murcia, Cajamurcia.

Fermoso, P. (1989) El modelo fenomenológico de investigación en pedagogía social. Educar, 14-15, 121-136.

Fox, D. (1981) El proceso de investigación en educación. Pamplona, Eunsa.

GarCía, L. y Martín, R. L. (2011) Convivir en la escuela. Una propuesta para su aprendizaje por competencias. Revista de Educación, 356, 531-555.

García, M. (2003) El ser humano protagonista de la educación, en GARCíA, M. (ed.) Claves de la Filosofía de la Educación. Madrid, Dykinson.

GENERALITAT VALENCIANA (2017) Memoria anual sobre la convivència escolar en la Comunitat Valenciana. Curso 2015-2016. Consultado el 12 de mayo de 2018, http://www.ceice. gva.es/documents/162793785/163278742/170616_INF_memoria-anual-convivencia. pdf/aa7c2c6e-e4fd-400f-b5c9-bb97c780085f.

Hall, B. P. y Tonna, B. (1989) El inventario Hall-Tonna. Colección Instituto de Ciencias de la Educación. Universidad de Deusto. San Sebastián, Trátalo.

Higgins C. (2010) The good life of teaching: An ethics of professional practice. Journal of Philosophy of Education, 44, 2-3.

IbáÑEZ-MARTín, J. A. (1992) La Filosofía de la Educación y el futuro de Europa, en Bárcena, E.; Gil, F.; Ibáñez-Martín, J. A.; Jover, G.; Ruiz Corbella, M. y Sacristán, D. La Filosofía de la Educación en Europa. Madrid, Dykinson, 11-21.

IbÁÑez-MARTín, J. A. (2013) Ética docente del siglo XXI: Nuevos desafíos. Edetania, 43, 17-31. IVE (2016) Portal estadístico de la Generalitat Valenciana. Consultado el 5 de enero de 2018. Recuperado de http://www.ive.es/.

Kemmis, S. y McTaggart, R. (1988) The action Research planner. Geelong, Victoria, Deakin University Press.

Kerlinger, F. N. (1981) Enfoque Conceptual de la Investigación del Comportamiento. México, Editorial Interamericana.

Llauradó, O. (2014) La escala de Likert: qué es y cómo utilizarla. Consultado el 4 de enero de 2016. https://www.netquest.com/blog/es/la-escala-de-likert-que-es-y-como-utilizarla.

Llopis, J. A. y BAlLESTER, R. (2001) Valores y actitudes en la educación. Teorías y estrategias educativas. Valencia, Tirant lo Blanch.

LÓPEZ-BARAJAS ZAYAS, E. (2015) Introducción a la metodología científica: (Siete piezas fáciles). Universidad Internacional de La Rioja.

LÓPEZ-JuRAdO, M. (2011) Educación para el siglo XXI. Bilbao, Desclée.

Marina, J. A.; Rodríguez de Castro, M. T. y Lorente, M. (2015) El nuevo paradigma de la adolescencia. Madrid: Centro Reina Sofía sobre Adolescencia y Juventud, FAD. Consultado el 20 de junio de 2018. http://adolescenciayjuventud.org/es/publicaciones/ coleccion-documentos/item/el-nuevo-paradigma-de-la-adolescencia.

Maslow, A. (1979) El hombre autorrealizado. Hacia una psicología del Ser. Barcelona, Kairós.

Medina, A. y Domínguez, M. C. (2015) Modelos didáctico-tecnológicos para la innovación educativa, en Cacheiro, M. L; SÁnchez, C. y González, J. M. Recursos tecnológicos en contextos educativos, 27-54.

Mena, I. y Valdés, A. (2008) Clima social escolar. Consultado el 12 de diciembre de 2018. http://ww2.educarchile.cl/UserFiles/P0001/File/clima_social_escolar.pdf. 
MARCOS GARCÍA VIDAL, M. ${ }^{a}$ CARMEN ORTEGA NAVAS Y JOSÉ MARÍA SOLA RECHE LA IMPORTANCIA DE LOS VALORES TRANSMITIDOS POR EL PROFESORADO DE SECUNDARIA...

MINISTERIO DE EDUCACIÓN (2010) Estudio estatal sobre la convivencia escolar en la educación secundaria obligatoria. Consultado el 20 de junio de 2018. https://sede.educacion.gob. es/publiventa/detalle.action?cod=13567.

OCDE (2013) Informe Talis. Estudio Internacional de la Enseñanza y el Aprendizaje. Consultado el 15 de febrero de 2018. http://www.mecd.gob.es/dctm/inee/internacional/ talis2013/talis2013informeespanolweb.pdf?documentId=0901e72b819e1729.

Olweus, D. (2005) Bullying en la escuela: datos e intervención. IX Reunión sobre Biología y Sociología de la Violencia: Violencia y Escuela. Centro Reina Sofia para el estudio de la violencia: Valencia, CAM.

Ortega, M. C. (2014) La inteligencia emocional, el desgaste profesional (burnout) y el engagement: implicaciones para los docentes, en CASTILLO, S. Reflexiones, análisis y propuestas sobre la Formación Secundaria, vol. 1, 145.

ORTEGA, P. (1996) Valores y educación. Barcelona, Ariel.

PeIRÓ, S. (2005) Indisciplina y violencia escolar. Alicante, Instituto Alicantino de Cultura.

PEIRÓ, S. (2009) Valores educativos y convivencia. España, Club Universitario.

PEIRÓ, S. (2012) Innovaciones sobre la formación inicial de profesores con relación a la educación en valores. REIFOP, 15 (1), 61-80.

PEIRÓ, S. (2015) La espiral de la violencia escolar: educar en la amistad para la paz. Alicante, ECU.

Peiró, S. y Ramos, M. C. (2013) Parents' Re-Education to Improve Students in Risk of Scholastic Misbehaviour \& School Failure. International Journal of Secondary Education, 1 (5), 31-38.

Pérez, G. (2004) Pedagogía social, educación social. Madrid, Narcea.

PÉrez, G. (2008) La educación como respuesta a los retos que plantea la escuela. Bordón $60(4), 15-29$.

Pestana, N. (2003) Nuevas Visiones sobre la formaci6n docente: EI caso de la reestructuración de un programa de actualización de los profesores universitarios. Educere, 6 (21), 46-53.

Ponce, R. S. y SARMiento, Á. S. (2017) ¿La educación cambia? Repensando el sentido y finalidad de una escuela para todos. Teoría de la Educación, Revista Interuniversitaria, 29 (2), 167-184.

Poulin, R.; Beaumont, C.; Blaya, C. y Frenette, E. (2015) Le climat scolaire: un point central pour expliquer la victimisation et la réussite scolaire. Canadian Journal of Education/ Revue canadienne de l'éducation, 38 (1), 1-23.

Quintana, J. M. (1992) Educación en valores y diseño curricular, en L.O.G.S.E. Perfiles para una nueva educación. ICE de la Universidad de Granada, 15-26.

RATHS, L. E.; HaRmin, M. y Simon, S. B. (1966) Values and Teaching: Working with values in the classroom. Ohio, Charles E. Merrill Publishing Co.

ROKEaCH, M. (1973) The nature of human values. New York, Free Press.

ROMAGNOLI, C.; Mena, I. y VALDÉs, A. (2007) ¿Qué son las habilidades socioafectivas y éticas? Chile, Ministerio de Educación.

Rossini, V. y PEIRÓ, S. (2015) Educación en valores en la escuela italiana y española, desde la perspectiva de educar ciudadanos. Revista Electrónica Interuniversitaria de Formación del Profesorado, 18 (3), 113-125.

SÁnchez, F. (1993) Psicología social. Madrid, McGraw-Hill.

SARABIA, B. (1992) El aprendizaje y la enseñanza de las actitudes, en Coll, C.; Pozo, J. I.; Sarabia, B. y VAlls, E. Los contenidos de la Reforma. Madrid, Santillana, 133-197. 
MARCOS GARCÍA VIDAL, M. ${ }^{a}$ CARMEN ORTEGA NAVAS Y JOSÉ MARÍA SOLA RECHE LA IMPORTANCIA DE LOS VALORES TRANSMITIDOS POR EL PROFESORADO DE SECUNDARIA...

SCHÖn, D. A. (1992) Formación de profesionales reflexivos. Barcelona, Paidós.

Ugalde, N. y Balbastre, F. (2013) Investigación cuantitativa e investigación cualitativa: buscando las ventajas de las diferentes metodologías de investigación. Ciencias Económicas, 31 (2), 179-187.

Vilar, J. (1991) Clarificación de valores, en MarTínez, M. y PUIG, J. M. La educación moral. Perspectivas de futuro y técnicas de trabajo. Barcelona, Graó, 33-43.

WoOlley, M. E. y Bowen, G. L. (2007) In the context of risk: Supportive adults and the school engagement of middle school students. Family Relations, 56 (1), 92-104. 
